\title{
Asymmetry of Motor Behavior and Sensory Perception: Which Comes First?
}

\author{
Lesley J. Rogers \\ School of Science and Technology, University of New England, Armidale, NSW 2351, Australia; \\ lrogers@une.edu.au
}

Received: 7 April 2020; Accepted: 28 April 2020; Published: 29 April 2020

check for updates

\begin{abstract}
By examining the development of lateralization in the sensory and motor systems of the human fetus and chick embryo, this paper debates which lateralized functions develop first and what interactions may occur between the different sensory and motor systems during development. It also discusses some known influences of inputs from the environment on the development of lateralization, particularly the effects of light exposure on the development of visual and motor lateralization in chicks. The effects of light on the human fetus are related in this context. Using the chick embryo as a model to elucidate the genetic and environmental factors involved in development of lateralization, some understanding has been gained about how these lateralized functions emerge. At the same time, the value of carrying out much more research on the development of the various types of lateralization has become apparent.
\end{abstract}

Keywords: development; motor asymmetry; visual lateralization; human fetus; chick embryo; sensory-motor interaction

\section{Introduction}

The introductory outline for this Special Issue raises the question as to whether asymmetry in perception generates asymmetrical motor behavior or whether motor asymmetry comes first and generates asymmetry of perception. In other words, do hand or limb preferences lead to asymmetries in behavior elicited by visual, auditory, olfactory, or tactile stimulation, or is it the other way around? Alternatively, do the various types of perceptual and motor asymmetry lateralize independently of each other?

Despite considerable research conducted on the ontogenesis of handedness in humans, we still have no conclusive evidence concerning its causation. In fact, turning away from the original single-gene hypothesis for the causation of handedness [1], because no evidence supports it [2], it is now accepted that multiple genetic and environmental factors interact in the ontogenesis of handedness [3-6]. Whether there are overlaps between any of the factors important during the ontogenesis of motor lateralization and those that are involved in the ontogenesis of ear and eye preferences seems unlikely, given that handedness is not correlated with either eye or ear preferences [7]. This absence of connection suggests that different processes determine sensory and motor asymmetries in humans.

Furthermore, research investigating associations between handedness and language, visuospatial attention, or face processing has failed to reveal convincing correlations or complementarities, even when these different measures have been taken from the same subjects [8-12]. This suggests that each of these asymmetrical brain functions is largely, if not entirely, generated by separate processes.

Since the relationships between these sensory and motor functions in humans have been discussed fully by others, it is my intention to present only relevant information from studies of non-human species. Although the relatively few studies conducted on non-human primates have assessed hand 
(or limb) preference and sensory lateralization on the same subjects, thereby permitting direct analysis of any associations, the following studies have done so, and they lend support to the evidence from humans, showing that sensory and motor asymmetry are not closely linked, if they are linked at all [13].

For example, from the assessment of eye and hand preferences in marmosets, it is evident that there is no obligatory link between eye preference and limb preference. Common marmosets grasp food with a preferred hand, either the left or right. Within a group, or population, there are equal numbers of left-hand and right-hand preferring marmosets [14-16], and each individual retains its hand preference throughout adulthood [17]. However, the same marmosets with either left- or right-hand preference were found to show a strong population bias to use the right eye to view familiar, non-arousing stimuli, assessed by the eye preferred to view each stimulus through a peephole $[18,19]$ Since viewing with the right eye shows initial and preferential use of the left hemisphere [19], the group preference is consistent with the known specialization of the left-hemisphere to process non-arousing stimuli and to categorize them [20], and this eye-hemisphere bias had no association with hand preference.

A similar preference to view familiar stimuli with the right eye has been shown in chimpanzees [21]. By contrast, the same chimpanzees showed a preference to view a model snake with their left eye, and hence use the right hemisphere to process an emotionally arousing stimulus [21]; discussed in [13]. No association was found between eye preference and hand preference in this study of chimpanzees [21]. Consistent with these findings, in a study on mouse lemurs by Scheumann and Zimmerman [22], no association was found between hand preference and lateralization of auditory processing: male mouse lemurs were found to turn their head to the right to attend to conspecific calls signaling negative valence and this bias was not associated with their hand preferences.

In these examples, at least, and for these particular tasks, asymmetry of sensory processing is unrelated to the asymmetry of motor action. It has been found, however, that hand preference in common marmosets is associated with structural asymmetry of the secondary somatosensory cortex, a brain region that deals with tactile processing and somatosensory discrimination [23]. The stronger the right-hand preference, the larger is this region of the brain (or vice versa). Therefore, although hand preferences in marmosets are not associated with eye preferences and, hence, with visual sensory processing, there could possibly be a link between somatosensory processing and hand preference. This would make some sense since primates use their hands to touch objects and so receive somatosensory inputs. At the very least, this result alerts us to the possibility that lateralized processing of sensory information may differ between the senses and also in its possible association with motor behavior.

As mentioned above, the question concerning the presence or absence of an association between sensory and motor asymmetries in humans has been addressed by examining the degree of correlation between hand preferences and a range of sensory processes [11,12,24]. It has also been addressed from an evolutionary perspective $[25,26]$, with a focus on which type of lateralization may have evolved first. Although these approaches have contributed important information, no clear answer to the question has emerged. Therefore, perhaps it would be appropriate to address it by studying development in early life, as follows.

\section{Development and Lateralization in Humans}

In the human fetus, asymmetry of arm movement with a right preference is present from as early as eight weeks post-conception [27] and sucking the thumb, also with a right preference, is present at 12 weeks [28-30], whereas asymmetry of the planum temporale, later to be the region involved in language, does not appear until the third trimester of gestation [31-33]. Hence, motor asymmetry develops before the asymmetry of the region of the brain associated with language (Figure 1). 
Human fetus

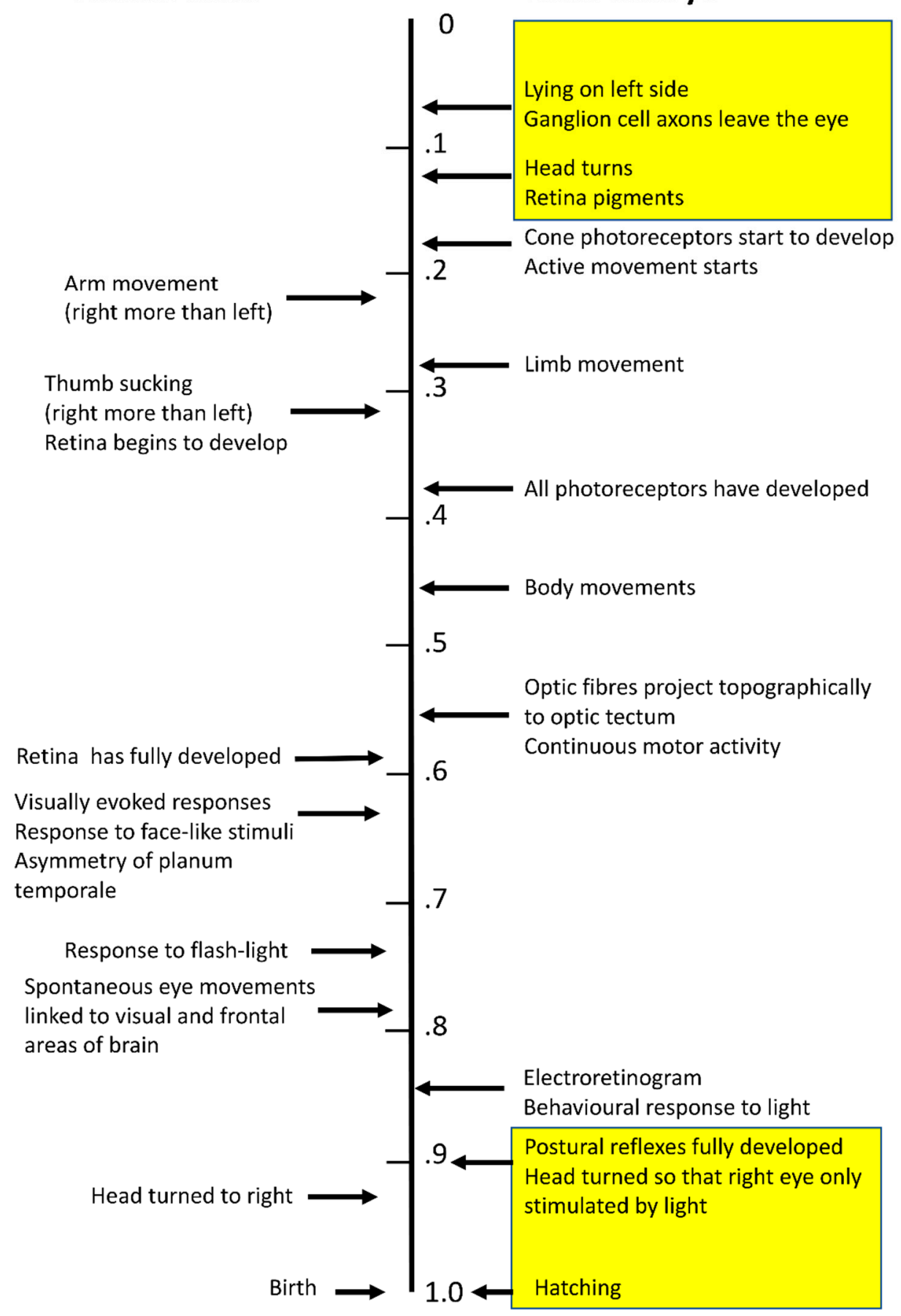

Figure 1. Events known to be relevant to lateralization of sensory and motor development are presented for the human fetus (left) and chick embryo (right). The timings have been scaled as ratios of the full-term gestational period or incubation period. Only the known events mentioned in the text are included, and these pertain to the development of visual and motor lateralization. The yellow boxes indicate the times when light exposure of the chick embryo is known to affect visual lateralization.

Motor asymmetries present during ftal development continue as handedness after birth [34]. In addition, a preference for the fetus, during late gestation, to turn its head to the right, as also occurs postnatally, is said to enhance motor asymmetry as a result of differential sensory-motor experience of the hands [35-37]. Based on this evidence, it has been hypothesized that sensory and motor systems 
interact, but handedness is considered to be the primary driver of the asymmetry in regions of the brain essential for language.

An alternative hypothesis is that handedness and language lateralization depend on genetic and ontogenetic processes that are largely, although not entirely, independent of each other (discussed by [10]). Consistent with this view, motor tasks using the fingers activate different brain regions than those activated during language tasks [38]. Furthermore, different gene sets are activated during the ontogeny of handedness and the ontogeny of language [39]. Studies of chimpanzees provide some additional support for this hypothesishand preferences in chimpanzees have been shown to be associated with structural asymmetries of the primary motor cortex, as expected, but not with areas of the brain homologous with language areas in humans [40].

As Lickliter [41] has pointed out, when studying sensory-motor development in humans, it is important to keep in mind that these systems do not start to develop at birth, but according to a sequence during gestation, and that the timing of each in the sequence is important for further sensory and motor development after birth. The generally accepted sequence of sensory development in humans is tactile, vestibular, chemosensory, auditory, and then visual. However, the retina of the eye of the fetus develops over the mid-gestational period [42] and visually-evoked responses can be recorded from preterm neonates as early as 24 weeks post-conception [43] and the response matures thereafter. Using magnetoencephalography, Eswaran and colleagues [44] were able to record responses evoked by visual stimuli in fetuses in utero from 28 weeks until birth at term. Another study recorded spontaneous eye movements in fetuses in utero aged between 30 and 36 weeks of gestation, and it showed that these movements were linked to functional networks in the visual and frontal cerebral areas [45]. Although the eye movements measured in this study were not driven by visual stimulation, it is known that between 36 and 40 weeks of gestation the fetus responds to the beam of a flashlight applied to the mother's abdomen; the light stimulation increased heart rate and movement of the fetus [46]. Furthermore, it has now been shown that the third trimester fetus responds by turning its head towards a stimulus of three illuminated dots [47]. In experiments not possible in humans but from research on rodents, it is known that light can reach the fetus in utero and that cells in the retina respond to the intensity of light [48]. Light-exposure of the rodent embryo has also been shown to affect eye development [49].

Hence, the onset of visually evoked responses might be considerably earlier than once thought, and so too might its possible interaction with other developing sensory and motor systems. The timing and amount of sensory stimulation in each of the senses is altered when birth occurs preterm, and this is said to have long-term effects on the developing premature brain (discussed by [41]). Also, enhanced or reduced sensory stimulation in one modality can affect the development of other sensory systems, as known from studies of infants who are blind early in life [50,51].

As far asis known, there is little information about the sequence of development of sensory asymmetry per se, expressed either before or after birth, nor is it known how possible sensory asymmetries interact with developing motor systems. However, a recent study by Buiatti et al. [52], who recorded EEG responses in newborns aged between 1 to 4 days, has shown significant asymmetry of responses to a simplified face-like stimulus. Responses to the face-like stimulus were stronger in the right hemisphere.

Also, as mentioned previously, it is known that the human fetus has a preference to turn its head to the right side and has a preference to move the right hand [53]. These preferences, recorded when the pre-term infant is placed in a supine position, are also present after birth. As Michel [54] has reasoned, this pre-birth asymmetry leads to the development of right-handedness (see also [55]) and that, after birth, sensory-motor interaction shapes further development of motor asymmetry and hemispheric specialization [56]. It has also been suggested that lateral differences in vestibular stimulation, resulting from the turned position of the fetus pre-parturition (right ear facing outwards), may lead to motor asymmetries, handedness, and footedness [57], and to the asymmetry of visual 
perception [58]. However, to my knowledge, no direct evidence has been found to support this hypothesized association.

\section{Studying Embryonic Development in a Model Species}

One way to discover more about the sequence of sensory-motor development is to study stages of sensory and motor development in non-human species. Since lateralized brain function is widespread amongst vertebrate species $[59,60]$, it is possible to choose from a range of species to study the development of sensory and motor asymmetries. Avian species are particularly suitable for such investigation because their development in ovo permits easy access to the embryo and the possibility of manipulating development in various ways. Indeed, studies of both chicken and the pigeon embryos and hatchlings have provided much information about the establishment and development of lateralized behavior and brain structures; studies on the chick embryo are discussed here, for research on lateralization in the pigeon see [5,61].

Asymmetry of sensory and motor functions is a clear characteristic of chicks and it is already apparent in the first and second weeks of life after hatching $[59,62,63]$. Consequently, the developing chick embryo provides a model system useful in addressing questions of sensory-motor development [64] and, since sensory and motor systems develop at different stages of embryonic incubation, it should be possible to gain some understanding of the sequence of asymmetrical development. Although, later in incubation, sensory and motor systems are integrated, they are to some degree separated in the initial stages of embryonic development.

\section{Asymmetry of Development of the Chick Embryo}

From very early in incubation (embryonic day E2 to E3) the chick embryo adopts an asymmetrical posture with its left-side lying against the yolk, and it remains in this position until day E12 of incubation when it undergoes torsion of the body position, and the head position relative to the body $[65,66]$. From day E19 of incubation until hatching on day E21, the embryo's head is turned so that the left eye is next to the embryo's body and the right eye is next to the membranes of the air sac. The visual system begins functioning from day E18, when an electroretinogram can first be detected, and the first behavioral responses to light are present [67], as shown in Figure 1. By day E19, light-stimulated potentials can be detected in the forebrain [65]. At this stage of development, light entering the egg through the shell and membranes stimulates the right eye only $[66,68]$. Hence, light stimulates the neural pathways connected to the right eye, thereby causing asymmetry in those regions of the brain processing visual information. Since, also at this stage of development, the thalamofugal visual system is forming connections to the forebrain, it is particularly affected by light stimulation. Within this system neural connections projecting from the left side of the thalamus, to which the right eye sends its inputs, are stimulated and consequently develop more connections to the forebrain visual regions than do their counterparts on the right side of the thalamus [69-72].

These asymmetries of the visual system, dependent on the effects of light exposure in the final stages of incubation, are manifested after hatching as right eye superiority in discriminating grains from pebbles [73,74], in the ability of chicks to discriminate left from right [75], in left-eye control of attack and copulation behavior [74], and left eye attention to novel stimuli [76]. Dependence of these lateralities on light exposure of the late-stage embryo has been demonstrated by comparing performance of chicks hatched from eggs incubated in darkness during the last three days before hatching, compared to those hatched from eggs exposed to light over the same three days; the dark-incubated chicks lack asymmetry of visual discrimination ability and attack and copulation behavior $[74,77,78]$. In fact, as little as $2 \mathrm{~h}$ of exposure to light on day E19 or E20 of incubation is sufficient to develop asymmetry of visual discrimination and $6 \mathrm{~h}$ of exposure to light ensures that this asymmetry is fixed and cannot be altered by subsequently exposing the left eye to light while occluding the right eye [63,74].

This evidence for light-induced asymmetry of the visual system and visual behavior points to the possibility that asymmetry of visual behavior develops after motor asymmetry of the embryo, since 
active movements of the embryo begin on day E4, leading up to the continuous activity of the embryo commencing on day E12 of incubation (summarized in [79] and see Figure 1). However, more recent research has shown an effect on visual lateralization of light exposure during the first three days of incubation, and hence, well before the visual pathways become functional $[68,80,81]$. For example, chicks presented with an array of grains show a preference to peck more grains on their left side than on their right side, provided they have been exposed to light for either the first three days or last three days of incubation, whereas chicks hatched from eggs that have received no light exposure show no side bias [80]. By contrast, chicks hatched from eggs incubated in darkness do show an asymmetry to distracting stimuli, responding more often to them when they are on the left side, whereas no such side bias is seen in chicks exposed to light either early or late during incubation [82]. These results indicate that both early and late exposure of the developing embryo to light has similar outcomes on at least some behavior, albeit via different cellular and/or subcellular routes.

There is at least one known difference between the effect of light early versus late in incubation: when tested binocularly, chicks hatched from eggs exposed to light during the late-stage of incubation repeatedly at the same pebble more often than did chicks exposed to light early in incubation or chicks incubated in the dark [81]. In other words, the effects of light during the two sensitive periods are not identical, and this is not surprising since they must depend on different ontogenetic processes.

It is possible, as Chiandetti and Vallortigara [81] have suggested, that the early effect of light influences the development of visual lateralization by modulating the activity of genes expressed in the development of lateralization. This could involve aspects of the Nodal cascade or be associated with nerve growth factor, which has a role in left-right patterning and a vital role in axial rotation of the early embryo [83]; also see [84] for genes involved in the expression of lateralization in fish.

There are two other possibilities, however. Already on day E2 of incubation, axons from the retinal ganglion cells begin to leave the retina and on day E3 pigmentation of the retina begins, the major structures of the eye have all formed and the retinal cells, including the ganglion and amacrine cells, begin to differentiate [85]. In fact, the local topographic specificity of the retina becomes fixed by day E3 [86]. Whether or not, at this stage of development, the retinal cells receive light-stimulated inputs that influence their development is not known but development of cone photoreceptors begins as early as day E4, even though the full complement of retinal photoreceptors does not appear until day E8-E10 [85]. Also, on day E3, the head of the embryo turns to the left side and, therefore, the eyes are already positioned for asymmetrical stimulation.

Whatever the means by which this early exposure to light generates lateralized visual behavior in newly hatched chicks, this research shows that visual lateralization is developing very early and either in association with, or in parallel with, the beginnings of motor development. Although it seems rather unlikely that motor activity is lateralized at this very early stage of development, that has not yet been studied.

The first active movements of the embryo are on day E4 and this motor activity involves only movements of the head and neck. It is followed by active movement of the trunk on day E5 and then by limb movements on day E6. However, body movements do not become obvious until day E10 or continuous until day E12, midway through incubation. Not until E19 are postural reflexes fully developed, at the same stage of development when light exposure (of the right eye) triggers the development of asymmetry of the thalamofugal visual system [65,87] (summarized in [79] chapter 1).

During the hatching process, chick embryos display anticlockwise rotation of the whole body and preferential use of the right foot to rotate the chick's body anticlockwise [88-90]. In other words, hatching involves asymmetrical use of the motor system and, in turn, this may determine the right-foot preference and leftwards turning bias found in chicks after they have hatched [89].

As known from experiments conducted by Casey and Lickliter [91] and Casey and Sleigh [92] on quail chicks (unfortunately not on domestic chicks although the results pertain to this species), monocular light stimulation during the late sensitive period just before hatching causes the development of population-level motor asymmetry after hatching. Exposing the late-stage embryo to visual 
experience via the right eye only (i.e., the natural condition) or via the left eye only induces population-level lateralization of motor behavior, measured as side bias in a Y-maze and foot preference to step up on to a platform, whereas no motor asymmetry is seen if both eyes receive exposure to enhanced visual inputs [92]. This demonstrates that visual stimulation can influence the development of motor asymmetry.

To answer the question, "Which comes first-motor or sensory asymmetry?": the evidence from studies of the chick embryo points to some aspects of light-associated sensory lateralization preceding motor lateralization. However, the critical, and over-riding, effect of light exposure during the sensitive period just before hatching may follow motor asymmetry or at least develop at the same time as it, and perhaps depends on sensory-motor interaction. To further understand these aspects of development, both sensory and motor lateralities need to be studied together in the same subjects. Also, it would be of benefit to develop new techniques to measure motor asymmetries during embryonic development.

\section{Comparing Species}

In Figure 1 the known developmental events relevant to visual and motor lateralization in the human fetus are juxtaposed to those of the chicken embryo. Gaps in the knowledge of these events in the human fetus are obvious. It is hoped that future research might gain some impetus from the known stages of development of lateralization in the chicken embryo.

This discussion has focused on visual sensory development, but asymmetry is present in other sensory systems of the post-hatched chick (e.g., olfaction [93,94]; audition [73]) and it would be worth investigating whether sensory stimulation of the embryo is involved in the asymmetrical development of the other sensory systems. We know that light exposure of the late-stage embryo has no effect on the lateralization of audition or olfaction, which is probably not surprising [78], but auditory and olfactory experience before hatching may influence the development of lateralization in these sensory systems.

Knowledge of the sequence of sensory-motor development is important since altering the sequence can have marked effects on sensory functioning and, hence, post-hatching behavior [95,96]. The chick provides a model for further investigation of the timing and extent of overlap and/or interaction between asymmetries in developing sensory and motor systems (for testing visual and auditory lateralization see [97]; for lateralization of olfaction, see [94,98]).

The ontogeny of the pigeon embryo is another model system for investigating these processes. Research on the pigeon embryo has already provided important comparative evidence since the pigeon is an altricial species, whereas the chicken is a precocial species. In the pigeon embryo, it is the other visual system, the tectofugal system, that develops asymmetry in response to light exposure $[61,99,100]$. Furthermore, in the pigeon, it has also been shown that light exposure enhances interhemispheric transfer of visual information [101].

\section{Conclusions}

At a time when the asymmetry of brain function was thought to a unique characteristic of humans, its manifestation in language, handedness, and tool use was considered by some researchers to be linked, and generated by a unitary cause, even due to a single gene locus, as Annett [102] suggested for handedness. Now we know that not only is this simple genetic model incorrect but also there are many different types of asymmetry in a broad range of vertebrate species. Indeed, there is evidence that functional lateralization of the brain evolved in early vertebrates [103] and that a basic plan of lateralized function can be found across vertebrate species [20,59]; viz., specialization of the left side of the brain, or hemisphere, to categorize stimuli and follow acquired rules, whereas the right side of the brain, or hemisphere, is specialized to respond to changes in the environment, including detection of novelty and predators, and to control social behavior $[59,104,105]$. The right hemisphere is also specialized to respond to negative emotional stimuli [106-108]. On to this 'Bauplan' were superimposed evolutionary developments, as more complex brains evolved or as behavior was adapted to specific environmental conditions. 
A similar argument has been made for hand/limb preference, for example, forelimb preferences are present not only in humans but also in other vertebrate species, and even in invertebrate species. As Versace and Vallortigara [109] reasoned, the evolution of forelimb preference was influenced by many selective pressures for different functions (e.g., tool-use, body posture, and communication-both vocal and gestural), and so it might depend on many genetic and environmental factors.

Viewing the evolution of brain asymmetry from the perspective of vertebrate species evolving towards humans, instead of from the starting point of human superiority, it is easy to conceive that a multitude of genes might be involved in its expression and, as discussed in this paper, genes involved in the development of asymmetry of sensory and motor systems may act either independently, or in interaction with each other, and also be influenced by inputs from the environment.

At this time, the field remains open for research and significant findings. This paper has discussed the onset of the development of lateralization in sensory and motor functions before birth or hatching with a view to gaining some insight into causations and interactions between these lateralized systems. No definitive answer has emerged, but the discussion makes it clear that the different asymmetries become apparent either as each follows an independent pathway of development or, potentially, by interactions between the different lateralized functions as they develop, and as they are manifested much earlier than once thought.

Funding: This research received no external funding.

Conflicts of Interest: The author declares no conflict of interest.

\section{References}

1. Annett, M. Left, Right, Hand and Brain: The Right Shift Theory; Erlbaum: London, UK, 1985.

2. McManus, C. Half a century of handedness research: Myths, truths; fictions, fact; backwards, but mostly forwards. Brain Neurosci. Adv. 2019, 3, 1-10. [CrossRef]

3. Ocklenburg, S.; Beste, C.; Güntürkün, O. Handedness: A neurogenetic shift of perspective. Neurosci. Biobehav. Rev. 2013, 37, 2788-2793. [CrossRef]

4. Ocklenburg, S.; Güntürkün, O. The Lateralized Brain: The Neuroscience and Evolution of Hemispheric Asymmetries; Academic Press: London, UK, 2018.

5. Güntürkün, O.; Ocklenburg, S. Ontogenesis of lateralization. Neuron 2017, 94, 249-263. [CrossRef]

6. Bishop, D.V.M. Cerebral asymmetry and language development: Cause, correlate, or consequence. Science 2013, 340, 1230531. [CrossRef] [PubMed]

7. Reiss, M.; Tymnik, G.; Kögler, W.; Reiss, G. Laterality of hand, foot, eye, and ear in twins. Laterality 1999, 4, 287-297. [CrossRef] [PubMed]

8. Corballis, M.C. The evolution of lateralized brain circuits. Front. Psychol. 2017, 8, 1021. [CrossRef] [PubMed]

9. Marzoli, D.; Lucafò, C.; Pagliara, A.; Cappuccio, R.; Brancucci, A.; Tommasi, L. Both right- and left-handers show a bias to attend others' right arm. Exp. Brain Res. 2014, 233, 415-424. [CrossRef]

10. Ocklenburg, S.; Beste, C.; Arning, L.; Peterburs, J.; Güntürkün, O. The ontogenesis of language lateralization and its relation to handedness. Neurosci. Biobehav. Rev. 2014, 43, 191-198. [CrossRef]

11. Badzakova-Trajkov, G.; Häberling, I.S.; Roberts, R.P.; Corballis, M.C. Complementarity and independent processes. PLoS ONE 2010, 5, e9682. [CrossRef]

12. Badzakova-Trajkov, G.; Corballis, M.C.; Häberling, I.S. Complementarity or independence of hemispheric specializations? A brief review. Neuropsychologia 2016, 93, 386-393. [CrossRef]

13. Rogers, L.J. Manual bias, behaviour, and cognition in common marmosets and other primates. In Cerebral Lateralization and Cognition: Evolutionary and Developmental Investigations of Behavioral Biases; Forrester, G., Hopkins, W.D., Hudry, K., Lindell, A.K., Eds.; Progress in Brain Research: PBR; Elsevier: Amsterdam, The Netherlands, 2018; Chapter 4; Volume 238, pp. 91-113.

14. Hook, M.A.; Rogers, L.J. Development of hand preferences in marmosets (Callithrix jacchus) and effects of ageing. J. Comp. Psych. 2000, 114, 263-271. [CrossRef] [PubMed]

15. Hook, M.A.; Rogers, L.J. Visuospatial reaching preferences of common marmosets: An assessment of individual biases across a variety of tasks. J. Comp. Psychol. 2008, 122, 41-51. [CrossRef] [PubMed] 
16. de Sousa, M.B.C.; Xavier, N.S.; da Silva, H.P.A.; de Oliveira, M.S.; Yamamoto, M.E. Hand preference study in marmosets (Callithrix jacchus) using food reaching tests. Primates 2001, 42, 57-66. [CrossRef]

17. Rogers, L.J. Hand and paw preferences in relation to the lateralized brain. Philos. Trans. R. Soc. Lond. B 2009, 364, 943-954. [CrossRef] [PubMed]

18. Hook-Costigan, M.A.; Rogers, L.J. Lateralization of hand, mouth and eye use in the common marmoset (Callithrix jacchus). Folia Primatologica 1995, 64, 180-191. [CrossRef] [PubMed]

19. Hook-Costigan, M.A.; Rogers, L.J. Eye preferences in common marmosets (Callithrix jacchus): Influence of age, stimulus, and hand preference. Laterality 1998, 3, 109-130. [CrossRef]

20. MacNeilage, P.; Rogers, L.J.; Vallortigara, G. Origins of the left and right brain. Sci. Am. 2009, 301, 60-67. [CrossRef]

21. Braccini, S.N.; Lambeth, S.P.; Schapiro, S.J.; Fitch, W.T. Eye preferences in captive chimpanzees. Anim. Cogn. 2012, 15, 971-978. [CrossRef]

22. Scheumann, M.; Zimmermann, E. Sex-specific asymmetries in communication sound perception are not related to hand preference in an early primate. BMC Biol. 2008, 6, 3. [CrossRef]

23. Gorrie, C.A.; Waite, P.M.E.; Rogers, L.J. Correlations between hand preference and cortical thickness in the secondary somatosensory (SII) cortex. Behav. Neurosci. 2008, 122, 1343-1351. [CrossRef]

24. Buckingham, G.; Carey, D.P. Attentional asymmetries - cause or consequence of human right handedness? Front. Psychol. 2014, 5, 1587. [CrossRef]

25. Uomini, N.T.; Ruck, L. Manual laterality and cognition through evolution: An archeological perspective. Prog. Brain Res. 2018, 238, 295-323.

26. Ruck, L. Manual praxis in stone-tool manufacture: Implications for language evolution. Brain Lang. 2014, 139, 68-83. [CrossRef]

27. de Kovel, C.G.F.; Ligo, S.; Karelbach, G.; Ju, J.; Cheng, G.; Fisher, S.; Francks, C. Left-right asymmetry of maturation rates in human embryonic neural development. Biol. Psychiatry 2017, 82, 204-212. [CrossRef]

28. Hepper, P.G.; Shahidullah, S.; White, R. Handedness in the human fetus. Neuropsychologia 1991, 29, 1107-1111. [CrossRef]

29. Hepper, P.G.; McCartney, G.R.; Shannon, E.A. Lateralised behavior in first trimester human foetuses. Neuropsychologia 1998, 36, 531-534. [CrossRef]

30. McCartney, G.; Hepper, P. Development of lateralized behavior in the human fetus from 12 to 27 weeks' gestation. Dev. Med. Child Neurol. 1999, 41, 83-86. [CrossRef]

31. Preis, S.; Jancke, L.; Schmitz-Hillebrecht, J.; Steinmetz, H. Child age and planum temporale asymmetry. Brain Cogn. 1999, 40, 441-452. [CrossRef]

32. Corballis, M.C. Early signs of brain asymmetry. Trends Cogn. Sci. 2013, 17, 554-555. [CrossRef]

33. Corballis, M.C. Left brain, right brain: Facts and fantasies. PLoS Biol. 2014, 12, e1001767. [CrossRef]

34. Hepper, P.G.; Wells, D.L.; Lynch, C. Prenatal thumb sucking is related to postnatal handedness. Neuropsychologia 2005, 43, 313-315. [CrossRef] [PubMed]

35. Ververs, I.A.; de Vries, J.I.; van Geijin, H.P.; Hopkins, B. Prenatal head position from 12-38 weeks. I. Developmental aspects. Early Hum. Dev. 1994, 39, 83-91. [CrossRef]

36. Konishi, Y.; Mikawa, H.; Suzuki, J. Asymmetrical head turning of preterm infants: Some effects on later postural and functional lateralities. Dev. Med. Child Neurol. 1986, 28, 450-457. [CrossRef]

37. Karim, A.K.M.R.; Proulx, M.J.; Likova, L.T. Anticlockwise or clockwise? A dynamic Perception-Action-Laterality model for directionality bias in visuospatial functioning. Neurosci. Biobehav. Rev. 2016, 68, 669-693. [CrossRef]

38. Klöppel, S.; van Eimeren, T.; Glauche, V.; Vongerichten, A.; Münchau, A.; Frackowiak, R.S.; Büchel, C.; Weiller, C.; Siebner, H.R. The effect of handedness on cortical motor activation during simple bilateral movements. Neuroimage 2007, 34, 274-280. [CrossRef]

39. Schmitz, J.; Lor, S.; Klose, R.; Güntürkün, O.; Ocklenburg, S. The functional genetics of handedness and language lateralization: Insights from gene ontology, pathway and disease association analyses. Front. Psychol. 2017, 8, 1144. [CrossRef]

40. Hopkins, W.D.; Cantalupo, C. Handedness in chimpanzees (Pan troglodytes) is associated with asymmetries of the primary motor cortex but not with homologous language areas. Behav. Neurosci. 2004, 118, 1176-1183. [CrossRef]

41. Lickliter, R. The integrated development of sensory organization. Clin. Perinatol. 2011, 38, 591-603. [CrossRef] 
42. Hendrickson, A. Development of retinal layers in prenatal human retina. Am. J. Ophthal. 2016, 161, $29-35$. [CrossRef]

43. Birch, E.E.; O'Connor, A.R. Preterm birth and visual development. Semin. Neonatol. 2001, 6, 487-497. [CrossRef]

44. Eswaran, H.; Lopwery, C.L.; Wilson, J.D.; Murphy, P.; Preissl, H. Functional development of the visual system in human fetus using magnetoencephalography. Exp. Neurol. 2004, 190 (Suppl. 1), 52-58. [CrossRef] [PubMed]

45. Schöpf, V.; Schlegl, T.; Jakab, A.; Kasprian, G.; Woitek, R.M.; Prayer, D.; Langs, D. The relationship between eye movement and vision develops before birth. Front. Hum. Neurosci. 2014, 8, 775. [PubMed]

46. Kiuchi, M.; Nagata, N.; Ikeno, S.; Terakawa, N. The relationship between the response to external light stimulation and behavioural states in the human fetus: How it differs from vibroacoustic stimulation. Early Hum. Dev. 2000, 58, 153-165. [CrossRef]

47. Reid, V.M.; Dunn, K.; Young, R.J.; Amu, J.; Donovan, T.; Reissland, N. The human fetus preferentially engages with face-like visual stimuli. Curr. Biol. 2017, 27, 1825-1828. [CrossRef] [PubMed]

48. Caval-Holme, F.; Feller, M.B. Gap junction coupling shapes the encoding of light in the developing retina. Curr. Biol. 2019, 29, 4024-4035. [CrossRef]

49. Rao, S.; Chun, C.; Fan, J.; Kofron, M.; Yang, M.B.; Hegde, R.S.; Ferrara, N.; Copenhagen, D.R.; Lang, R.A. A direct melanopsin-dependent fetal light response regulates mouse eye development. Nature 2013, 494, 243-247. [CrossRef]

50. Lessard, N.; Paré, M.; Lepore, F.; Lassonde, M. Early-blind human subjects localize sound sources better than sighted subjects. Nature 1998, 395, 278-280. [CrossRef]

51. Bavelier, D.; Neville, H.J. Cross-modal plasticity: Where and how? Nat. Rev. Neurosci. 2004, 3, 443-452. [CrossRef]

52. Buiatti, M.; di Giorgio, E.; Piazza, M.; Polloni, C.; Menna, G.; Taddei, F.; Baldo, E.; Vallortigara, G. Cortical route for facelike pattern processing in human newborns. Proc. Nat. Acad. Sci. USA 2019, 116, 4625-4630. [CrossRef]

53. Ververs, I.A.; de Vries, J.I.; van Geijin, H.P.; Hopkins, B. Prenatal head position from 12-38 weeks. II. The effects of foetal orientation and placental localization. Early Hum. Dev. 1994, 39, 93-100. [CrossRef]

54. Michel, G.F. Right-handedness: A consequence of infant supine head-orientation preference? Science 1981, 212, 685-687. [CrossRef]

55. Michel, G.F.; Harkins, D.A. Postural and lateral asymmetries in the ontogeny of handedness during infancy. Dev. Psychobiol. 1986, 19, 247-258. [CrossRef] [PubMed]

56. Ferre, C.L.; Babik, I.; Michel, G. A perspective on the development of hemispheric specialization, infant handedness, and cerebral palsy. Cortex 2020, 127, 208-220. [CrossRef] [PubMed]

57. Previc, F.H. A general theory concerning the prenatal origins of cerebral lateralization in humans. Psychol. Rev. 1991, 98, 299-334. [CrossRef] [PubMed]

58. Previc, F.H. Functional specialization in the lower and upper visual fields in humans: Its ecological origins and neurophysiological implications. Behav. Brain Sci. 1990, 13, 519-542. [CrossRef]

59. Rogers, L.J.; Vallortigara, G.; Andrew, R.J. Divided Brains: The Biology and Behaviour of Brain Asymmetries; Cambridge University Press: Cambridge, UK, 2013.

60. Vallortigara, G.; Rogers, L.J. A function of the bicameral mind. Cortex 2020, 124, 274-285. [CrossRef]

61. Ocklenburg, S. Güntürkün, OHemispheric asymmetries: The comparative view. Front. Psychol. $2012,3,5$. [CrossRef]

62. Vallortigara, G. Comparative neuropsychology of the dual brain: A stroll through left and right animals' perceptual worlds. Brain Lang. 2000, 73, 189-219. [CrossRef]

63. Rogers, L.J. Light input and the reversal of functional lateralization in the chicken brain. Behav. Brain Res. 1990, 38, 211-221. [CrossRef]

64. Vallortigara, G.; Chiandetti, C.; Sovrano, V.A. Brain asymmetry (animal). WIREs Cogn. Sci. 2011, 2, $146-157$. [CrossRef]

65. Freeman, B.M.; Vince, M.A. Development of the Avian Embryo: A Behavioural and Physiological Study; Chapman and Hall: London, UK, 1974. 
66. Tolhurst, B. Development of the chick embryo in relation to the shell, yolk, albumen and extra-embryonic membranes. In Development of the Avian Embryo: A Behavioural and Physiological Study; Freeman, B.M., Vince, M.A., Eds.; Chapman and Hall: London, UK, 1974; Appendix 2.

67. Thanos, S.; Bonhoeffer, F. Axonal arborization in the developing chick retinotectal system. J. Comp. Neurol. 1987, 261, 155-164. [CrossRef] [PubMed]

68. Chiandetti, C.; Lemaire, B.S.; Versace, E.; Vallortigara, G. Early- and late-light embryonic stimulation modulates similarly chicks' ability to filter out distractors. Symmetry 2017, 9, 84. [CrossRef]

69. Rogers, L.J.; Sink, H.S. Transient asymmetry in the projections of the rostral thalamus to the visual hyperstriatum of the chicken, and reversal of its direction by light exposure. Exp. Brain Res. 1988, 70, 378-384. [CrossRef] [PubMed]

70. Rogers, L.J.; Bolden, S.W. Light-dependent development and asymmetry of visual projections. Neurosci. Lett. 1991, 121, 63-67. [CrossRef]

71. Deng, C.; Rogers, L.J. Differential contributions of the two visual pathways to functional lateralization in chicks. Behav. Brain Res. 1997, 87, 173-182. [CrossRef]

72. Rogers, L.J.; Deng, C. Light experience and lateralization of the two visual pathways in the chick. Behav. Brain Res. 1999, 98, 277-287. [CrossRef]

73. Rogers, L.J.; Anson, J.M. Lateralisation of function in the chicken fore-brain. Pharm. Biochem. Behav. 1979, 10, 679-686. [CrossRef]

74. Rogers, L.J. Light experience and asymmetry of brain function in chickens. Nature 1982, 297, $223-225$. [CrossRef]

75. Chiandetti, C.; Vallortigara, G. Effects of embryonic light stimulation on the ability to discriminate left from right in the domestic chick. Behav. Brain Res. 2009, 198, 240-246. [CrossRef]

76. Chiandetti, C. Pseudoneglect and embryonic light stimulation in the avian brain. Behav. Neurosci. 2011, 125, 775-782. [CrossRef]

77. Zappia, J.V.; Rogers, L.J. Light experience during development affects asymmetry of forebrain function in chickens. Dev. Brain Res. 1983, 11, 93-106. [CrossRef]

78. Rogers, L.J. Development and function of lateralization in the avian brain. Brain Res. Bull. 2008, 76, $235-244$. [CrossRef] [PubMed]

79. Rogers, L.J. The Development of Brain and Behaviour in the Chicken; CAB International: Oxon, UK, 1995.

80. Chiandetti, C.; Galliussi, J.; Andrew, R.J.; Vallortigara, G. Early-light embryonic stimulation suggests a second route, via gene activation, to cerebral lateralization in vertebrates. Sci. Rep. 2013, 3, 2701. [CrossRef] [PubMed]

81. Chiandetti, C.; Vallortigara, G. Distinct effect of early and late embryonic light-stimulation on chicks' lateralization. Neuroscience 2019, 414, 1-7. [CrossRef]

82. Chiandetti, C. Manipulation of strength of cerebral lateralization via embryonic light stimulation in birds. In Lateralized Brain Functions: Methods in Human and Non-Human Species; Rogers, L.J., Vallortigara, G., Eds.; Neuromethods: New York, NY, USA, 2017; Volume 122, pp. 611-631.

83. Manca, A.; Capsoni, S.; Di Luzio, A.; Vignone, D.; Malerbra, F.; Paoletti, F.; Brandi, R.; Arisi, I.; Cattaneo, A.; Levi-Montalcini, R. Nerve growth factor regulates axial rotation during early stages of chick embryo development. Proc. Natl. Acad. Sci. USA 2012, 109, 2009-2014. [CrossRef]

84. Petrazzini, M.E.M.; Sovrano, V.; Vallortigara, G.; Messina, A. Brain and behavioral asymmetry: A lesson from fish. Front. Neuroanat. 2020, 14, 11. [CrossRef]

85. Doh, S.T.; Hao, H.; Loh, S.C.; Patel, T.; Tawil, H.Y.; Chen, D.K.; Pashkova, A.; Shen, A.; Wang, H.; Cai, L. Analysis of retinal development in chick embryo by immunohistochemistry and in ovo electroporation techniques. BMC Dev. Biol. 2010, 10, 8. [CrossRef]

86. De Long, G.R.; Coulombre, A.J. Development of the retinotectal topographic projection in the chick embryo. Exp. Neurol. 1965, 13, 351-363. [CrossRef]

87. Hamburger, V.; Hamilton, H.L. A series of normal stages in the development of the chick embryo. J. Morph. 1951, 88, 49-92. [CrossRef]

88. Casey, M.B.; Martino, C. Asymmetrical hatching behaviors influence the development of postnatal laterality in domestic chicks (Gallus gallus). Dev. Psychobiol. 2000, 34, 1-12. [CrossRef]

89. Casey, M.B. Asymmetrical hatching behaviors: The development of postnatal motor laterality in three precocial bird species. Dev. Psychobiol. 2005, 47, 123-125. [CrossRef] 
90. Casey, M.B.; Sleigh, M.J. Cross-species investigations of prenatal experience, hatching behavior, and postnatal behavioral laterality. Dev. Psychobiol. 2001, 35, 84-91. [CrossRef] [PubMed]

91. Casey, M.B. and Lickliter, R. Prenatal visual experience influences the development of turning bias in bobwhite quail chicks (Colinus virginianus). Dev. Psychobiol. 1998, 32, 327-338. [CrossRef]

92. Casey, M.B.; Sleigh, M.J. Prenatal visual experience induces postnatal motor laterality in Japanese quail chicks (Coturnix coturnix japonica). Dev. Psychobiol. 2014, 56, 489-497. [CrossRef] [PubMed]

93. Vallortigara, G.; Andrew, R.J. Olfactory lateralization in the chick. Neuropsychologia 1994, 32, 417-423. [CrossRef]

94. Rogers, L.J.; Andrew, R.J.; Burne, T.H.J. Light exposure of the embryo and development of behavioural lateralisation in chicks: I. Olfactory responses. Behav. Brain Res. 1998, 97, 195-200. [CrossRef]

95. Honeycutt, H.; Lickliter, R. Order-dependent timing of unimodal and multimodal stimulation affects prenatal auditory learning in bobwhite quail embryos. Dev. Psychobiol. 2001, 38, 1-10. [CrossRef]

96. Banker, H.; Lickliter, R. Effects of early and delayed visual experience on intersensory development in bobwhite quail chicks. Dev. Psychobiol. 1993, 26, 155-170. [CrossRef]

97. Rogers, L.J. Eye and ear preferences. In Lateralized Brain Functions: Methods in Human and Non-Human Species; Rogers, L.J., Vallortigara, G., Eds.; Neuromethods: New York, NY, USA, 2017; Volume 122, pp. 79-102.

98. Siniscalchi, M. Olfactory lateralization. In Lateralized Brain Functions: Methods in Human and Non-Human Species; Rogers, L.J., Vallortigara, G., Eds.; Neuromethods: New York, NY, USA, 2017; Volume 122, pp. $103-120$.

99. Letzner, S.; Güntürkün, O.; Lor, S.; Pawlik, R.J.; Manns, M. Visuospatial attention in the lateralised brain of pigeons-A matter of ontogenetic light experiences. Sci. Rep. 2017, 7, 15547. [CrossRef]

100. Manns, M.; Ströckens, F. Functional and structural comparison of visual lateralization in birds-Similar but still different. Front. Psychol. 2014, 25, 5-206. [CrossRef]

101. Letzner, S.; Patzke, N.; Verhaal, J.; Manns, M. Shaping a lateralized brain: Asymmetrical light experience modulates access to visual interhemispheric information in pigeons. Sci. Rep. 2014, 4, 4253. [CrossRef] [PubMed]

102. Annett, M. Handedness and Brain Asymmetry: The Right Shift Theory; Psychology Press: New York, NY, USA, 2002.

103. Andrew, R.J. The earliest origins and subsequent evolution of lateralization. In Comparative Vertebrate Lateralization; Rogers, L.J., Andrew, R.J., Eds.; Cambridge University Press: Cambridge, UK, 2002; pp. 70-93.

104. Karenina, K.; Giljov, A.; Ingram, J.; Rowntree, V.J.; Malashichev, Y. Lateralization of mother-infant interactions in a diverse range of mammal species. Nat. Ecol. Evol. 2017, 1, 0030. [CrossRef]

105. Vallortigara, G. Right hemisphere advantage for social recognition in the chick. Neuropsychologica 1992, 30, 761-768. [CrossRef]

106. d'Ingeo, S.; Quaranta, A.; Siniscalchi, M.; Stomp, M.; Coste, C.; Bagnard, C.; Hausberger, M.; Cousillas, H. Horses associate individual human voices with the valence of past interactions: A behavioural and electrophysiological study. Sci. Rep. 2019, 9, 11568. [CrossRef] [PubMed]

107. Siniscalchi, M.; Quaranta, A.; Rogers, L.J. Hemispheric specialization in dogs for processing different acoustic stimuli. PLoS ONE 2008, 3, e3349. [CrossRef] [PubMed]

108. Smith, A.V.; Proops, L.; Grounds, K.; Wathan, J.; Scott, S.K.; McComb, K. Domestic horses (Equus caballus) discriminate between negative and positive human nonverbal vocalisations. Sci. Rep. 2018, 8, 13052. [CrossRef]

109. Versace, E.; Vallortigara, G. Forelimb preferences in human beings and other species: Multiple models for testing hypotheses on lateralization. Front. Psychol. 2015, 6, 233. [CrossRef]

(C) 2020 by the author. Licensee MDPI, Basel, Switzerland. This article is an open access article distributed under the terms and conditions of the Creative Commons Attribution (CC BY) license (http://creativecommons.org/licenses/by/4.0/). 